\title{
Development and experience with a technical elective course "fluid flows in nature"
}

\author{
J. A. Schetz \\ Department of Aerospace and Ocean Engineering, \\ Virginia Polytechnic Institute and State University, \\ Blacksburg, Virginia, USA
}

\begin{abstract}
This course was designed to build upon and broaden a basic, traditional engineering knowledge of fluid flows into new and stimulating areas concerning a wide variety of natural occurrences and phenomena that involve fluid motions in important ways. Topics covered include: drag of sessile systems and motile animals; gliding and soaring; flying and swimming; internal flows in organisms; low Reynolds number flows; fluid-fluid interfaces; unsteady flows in nature; atmospheric flows and wind engineering; and environmental fluid mechanics. The course is intended for upper-level students in engineering and science and presumes a background in the fundamentals of fluid flows at the level of a first engineering course in fluid mechanics. It has proven popular with students majoring in mechanical, civil, aerospace and ocean engineering, with occasional students from mathematics and sciences. An unexpected, but welcome and powerful, benefit occurs in the form of reinforcing and deepening student understanding of traditional topics in engineering fluid mechanics by contrast with the often very different situations encountered in nature. An online version of the course was introduced for the Spring Semester of 2006.
\end{abstract}

Keywords: fluid flows in nature, flying and swimming, environmental fluid mechanics, wind engineering.

\section{Introduction}

In 1998, a new course was designed to build upon and broaden a basic, traditional engineering knowledge of fluid flows into new and stimulating areas concerning a wide variety of natural occurrences and phenomena that involve 
fluid motions in important ways. Topics covered included: continuity, pressure and momentum and applications in nature; drag of sessile systems and motile animals; gliding and soaring; flying and swimming; internal flows in organisms; low Reynolds number flows; fluid-fluid interfaces; unsteady flows in nature; atmospheric flows and wind engineering; and environmental fluid mechanics. The course involved classroom lectures using an interesting, but only partially suitable, text supplemented by handouts and lecture notes, an extensive internet website, complementary films and videos and four laboratory experiments.

The laboratory experiments were intended to demonstrate important concepts and also to familiarize the students with specialized facilities outside of their major fields of study. The experiments covered drag measurement of a trout model in a towing tank, pressure distributions and surface flow visualization on an airfoil in a wind tunnel, flow visualization of stall in a smoke tunnel, and flow in flooded, wooded areas in a river flume.

Useful materials for the website and handouts have been found in newspapers and magazines and also in scientific magazines such as American Scientist and Mechanical Engineering.

The course was and is intended for upper-level undergraduate and beginning graduate students in engineering and science and presumes at least a background in the fundamentals of fluid flows at the level of a first engineering course in fluid mechanics. It has proven popular with students majoring in mechanical, civil, aerospace and ocean engineering, with occasional students from mathematics and sciences. Typical enrollments averaged about 60 students every Spring Semester through 2005. Anonymous student evaluations are very supportive.

An unexpected, but welcome and powerful, benefit occurs in the form of reinforcing and deepening student understanding of traditional topics in engineering fluid mechanics by contrast with the often very different situations encountered in nature. One example is the better understanding of high Reynolds flows resulting from a detailed study of low Reynolds flows in nature.

In 2005, a decision was reached to prepare an Online version of this course. This decision was prompted by a number of factors. First, there is a desire to offer the course more frequently and to a wider group of potential students. The Online course can be offered in both the Fall and Spring Semesters. Also, our university has an extensive Distance Learning program with many off-campus engineering graduate students who can now access the course. Second, the textbook originally required of all students, Life in Moving Fluids by Steven Vogel, lacked coverage of some important topics desired here, such as environmental flows. And, it is devoid of photographs which are deemed critical in this subject area. The use of Handouts is severely limited by the cost of color copies. In principle, these issues can be handled on a website, and that was tried. But, this contributed to the next issue. The third and last matter of concern was the disorganized arrangement of the instructional material. The students were dealing with a textbook, handouts, a website, videos shown in class and four laboratory experiments. This proved less than optimal. The hope is that the 
Online course can bring all of the instructional material together in one easily accessible place.

\section{Online course format}

The basic format of the new online course centers on the use of a large number of PowerPoint slides with a voice-over narration implemented with Breeze plugin software for PowerPoint. All of the instructional material, except for the videos, was incorporated into these slides as a single source for the students. Two sample slides are included here at the end of the paper. These slides are only accessible to students registered for the course because of copyright issues. A Blackboard website hosts this material as well as: Announcements, Course Documents, a Week-by-week study plan, Assignments, Exams, and Grades.

The main sources of instructional materials for the narrated slides were the books (in alphabetical order), multimedia sources, scientific magazines, and newspapers listed here:

Anderson, J.D., Introduction to Flight, Third Edition, McGraw Hill: New York, 1989.

Azuma, A., Biokinetics of Flying and Swimming, Springer: Tokyo, 1993.

Hertel, H., Structure-Form-Movement, Reinhold: New York, 1966.

Hoerner, S.F., Fluid-Dynamic Drag, Hoerner Fluid Dynamics: Vancouver, 1965.

Munson, B.R., Young, D.F. and Okiishi, T.H., Fundamentals of Fluid Mechanics, Second Edition, John Wiley \& Sons: New York, 1994.

Potter, M.C. and Wiggert, D.C., Mechanics of Fluids, Third Edition, Brooks/Cole: Pacific Grove, 2001.

Schetz, J.A., Boundary Layer Analysis, Prentice Hall: Englewood Cliffs, 1993.

Tennekes, H., The Simple Science of Flight, The MIT Press: Cambridge, 1997.

Tricker, R.A.R. and Tricker, B.J.K., The Science of Movement, American Elsevier: New York, 1967.

Vogel, S., Life in Moving Fluids, Second Edition, Princeton University Press: Princeton, 1994.

Multimedia Fluid Mechanics, Cambridge University Press, 2000.

American Scientist, Mechanical Engineering, USA Today, Wall Street Journal, and New York Times

The slide presentations are complemented by a number of excellent videos that are critical in a course such as this one. In particular, it is simply not workable to discuss topics such as flying and swimming or tornadoes with static materials alone. First, a selection of the excellent films produced in the 1950's by the National Committee for Fluid Mechanics are employed: Pressure Fields and Fluid Acceleration, Fluid Dynamic Drag, Fundamentals of Boundary Layers, Turbulence, Vorticity, Low Reynolds Number Flows, Waves in Fluids (first 20 minutes), and Stratified Flows. These are now conveniently available online at: 
http://web.mit.edu/fluids/www/Shapiro/ncfmf.html. Students are also referred to Form Drag, Lift and Propulsion at: www.iihr.uiowa.edu/products/pubvid/RouseMovies/pgm5.mpg and the videos on the Project Ornithopter website at: www.ornithopter.net/index e.html. In addition, abridged versions of Secrets of the Tornado by The Tornado Project (www.tornadoproject.com) and Flying High by Scientific American Frontiers on PBS Home Video have been posted on a website at our university accessible only to students registered for this course. A few other very short film clips are also posted.

The slide presentations and the videos and films listed above now form the body of instructional materials used in the online version of the course. We have not found a workable way to include the laboratory experiments developed for the classroom version. We are considering making professional videos of the labs conducted at our university for inclusion in the online course at a later date.

The next important issue in any course is homework assignments. It has proven possible to find quite suitable problems and their solutions mostly in the Vogel; Munson, Young and Okiishi; Schetz; and Potter and Wiggert books, as well as in Theory and Problems of Fluid Mechanics and Hydraulics in Schaum's Outline Series published by McGraw Hill and miscellaneous other sources. A sample homework problem taken from the Munson, Young and Okiishi book is reproduced below.

\footnotetext{
Some animals have learned to take advantage of the Bernoulli effect without having read a fluid mechanics book. For example, a typical prairie dog burrow contains two entrancesa flat front door, and a mounded back door as shown in Fig. P3.13. When the wind blows with velocity $V_{0}$ across the front door, the average velocity across the back door is greater than $V_{0}$ because of the mound. Assume the air velocity across the back door is $1.07 V_{0}$. For a wind velocity of $6 \mathrm{~m} / \mathrm{s}$. what pressure differences, $p_{1}-p_{2}$, is generated to provide a fresh air flow within the burrow?
}

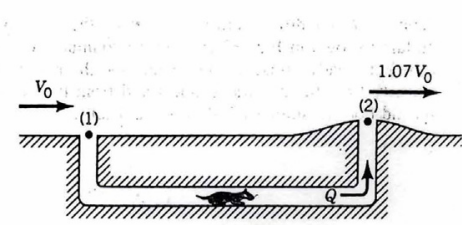

FIGURE P3.13

Figure 1: Homework problem used in the Fluid Flows in Nature course taken from Munson, Young and Okiishi, 1994.

Students turn in their homework for each week via e-mail to a temporary email address, and the grades are posted on the Blackboard site.

Finally, all exams are given as a combination of Multiple-Choice and True/False questions. Perhaps surprisingly, the students are generally comfortable with that format. The writer has also found that format effective in probing student understanding. Further, that format has the great virtue of at least minimizing student complaints over "partial credit" in grading. With that format, the answers are simply either right or wrong. Students turn in their exam solutions via e-mail to a temporary e-mail address, and the grades are posted on the Blackboard site. 
Homework and exams are covered by our university Honor Code to insure integrity.

With all of this, the week-by-week semester (15 week) course outline is shown in Table 1 below.

Table 1: $\quad$ Fluid flows in nature online course schedule.

\begin{tabular}{|c|c|c|}
\hline Week & Slide Presentations & Supplements \\
\hline 1 & $\begin{array}{l}\text { Introduction (15 slides) } \\
\text { Continuity and in Nature (7) } \\
\text { Pressure and Momentum (18) }\end{array}$ & $\begin{array}{l}\text { Pressure Fields and } \\
\text { Fluid Acceleration, } \\
\text { Fluid Dynamic Drag I }\end{array}$ \\
\hline 2 & Drag, Part A (29) & Fluid Dynamic Drag II,III \\
\hline 3 & Drag, Part B (30) & $\begin{array}{l}\text { Fluid Dynamic Drag IV, } \\
\text { Fund. of Bound. Layers }\end{array}$ \\
\hline 4 & Boundary Layers in Nature (25) & $\begin{array}{l}\text { Turbulence, } \\
\text { Vorticity I }\end{array}$ \\
\hline 5 & Vortices in Nature (39) & $\begin{array}{l}\text { Vorticity II, } \\
\text { Tornado video }\end{array}$ \\
\hline 6 & Lift, Gliding and Soaring A (29) & $\begin{array}{l}\text { Form Drag, Lift and } \\
\text { Propulsion video }\end{array}$ \\
\hline 7 & MIDTERM EXAM & \\
\hline 8 & Lift, Gliding and Soaring B (34) & X-Ray Flying Filmclip \\
\hline 9 & Thrust, Flying and Swimming (65) & Flying High video \\
\hline 10 & Internal Flows (53) & Bronchial CFD Filmclip \\
\hline 11 & Low Reynolds Number Flows (40) & Low Re Flows \\
\hline 12 & Unsteady and Interfacial Flows (56) & $\begin{array}{l}\text { Waves in Fluids (20 min.) } \\
\text { Stratified Flow }\end{array}$ \\
\hline 13 & Environmental Fluid Mech. (62) & \\
\hline 14 & Wind Engineering (55) & Flow Over Buildings \\
\hline 15 & FINAL EXAM & \\
\hline
\end{tabular}




\section{Current status}

At the time this paper is being written, students are just beginning the course for the first time in the online format. One possible indicator of success is that more than 130 students have registered for the course in this format. That is more than double the average enrolment for the course taught in a classroom format for the first eight times. At the conference, the results of anonymous student evaluations and instructor impressions will be presented.

\section{Exasrjples of Flujd Flows in Nature}

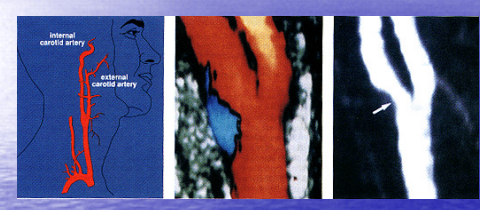

Flow behavior in arteries has been shown to affect the health of the artery. For example, a low wall shear causes a decrease in the health of the artery wall. Local separation causes low wall shear.

$$
\text { From American Scientist }
$$

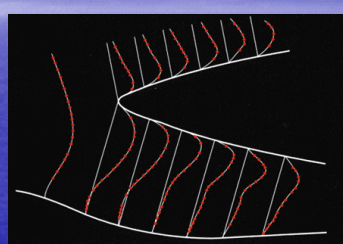

Laboratory Simulation

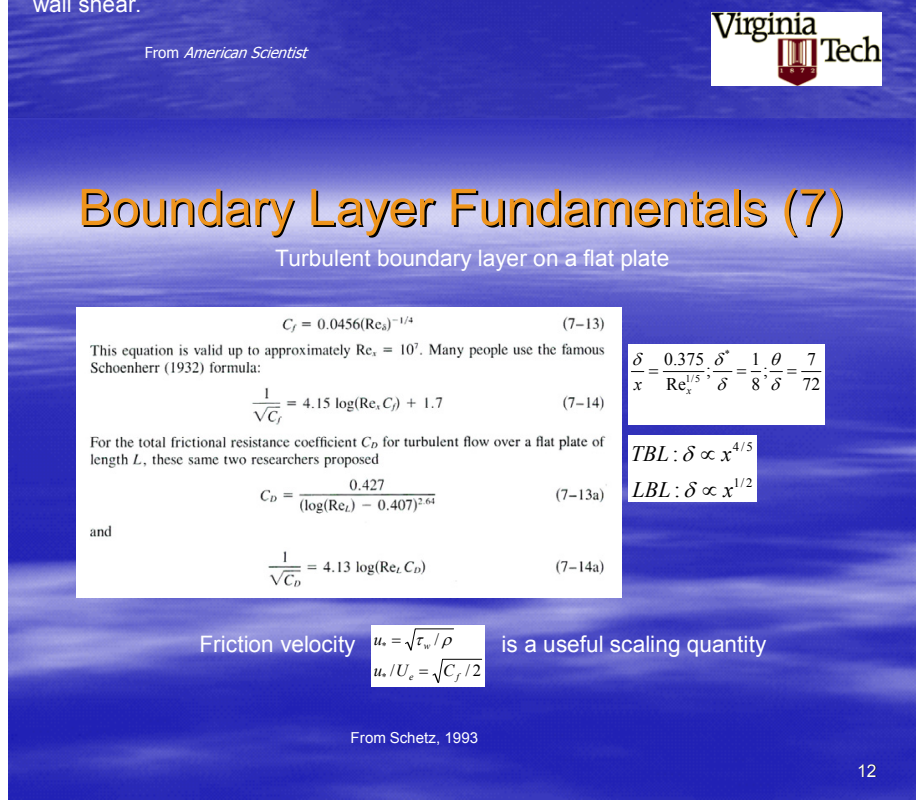

Figure 2: $\quad$ Sample sides. 